\title{
28 Research Suare \\ Direct growth of copper(I) oxide nanocubes on graphitic carbon nitrides enhancing aqueous carbon dioxide photoreduction
}

Hyunjoon Song ( $\sim$ hsong@kaist.ac.kr)

Korea Advanced Institute of Science and Technology https://orcid.org/0000-0002-1565-5697

Byeonghoon Choi

Korea Advanced Institute of Science and Technology

Chan Kyu Lim

Korea Advanced Institute of Science and Technology https://orcid.org/0000-0003-2840-0025

Minjun Kim

Korea Advanced Institute of Science and Technology

Bumjin Park

https://orcid.org/0000-0001-9764-9129

Won-Woo Park

Ulsan National Institute of Science and Technology

Oh-Hoon Kwon

Ulsan National Institute of Science and Technology https://orcid.org/0000-0001-7114-8617

Hee-Seung Lee

KAIST https://orcid.org/0000-0003-0004-1884

Article

Keywords:

Posted Date: December 21st, 2021

DOI: https://doi.org/10.21203/rs.3.rs-1154699/v1

License: (1) (1) This work is licensed under a Creative Commons Attribution 4.0 International License.

Read Full License 


\section{Abstract}

Semiconductor hybrid structures containing multiple components have been considered an ideal photocatalyst design to generate long-lived charge-separated states. Particularly for the reactions requiring high activation energies, such as a $\mathrm{CO}_{2}$ reduction reaction $\left(\mathrm{CO}_{2} \mathrm{RR}\right)$, the reaction activity is highly susceptible to the catalyst component and morphology. In this study, we selected g- $\mathrm{C}_{3} \mathrm{~N}_{4}$ and $\mathrm{Cu}_{2} \mathrm{O}$ as photocatalytic components having bandgaps suitable for $\mathrm{CO}_{2} \mathrm{RR}$. Then, we tried to form good electric junctions between two domains by direct growth of $\mathrm{Cu}$ on $\mathrm{g}-\mathrm{C}_{3} \mathrm{~N}_{4}$ using a polyol process. The resulting g$\mathrm{C}_{3} \mathrm{~N}_{4} / \mathrm{Cu}_{2} \mathrm{O}$ hybrid was employed as photocatalysts in an aqueous medium without hole acceptors. The catalyst exhibited a noticeable activity $\left(5.4 \mathrm{mmol} \mathrm{g}_{\mathrm{cat}^{-1}} \mathrm{~h}^{-1}\right)$ and quantum yield (3.7\%) with a nearly quantitative selectivity for $\mathrm{CH}_{4}$ production, superior to any other photocatalysts for $\mathrm{CO}_{2} \mathrm{RR}$. The strong coordination of $\mathrm{g}-\mathrm{C}_{3} \mathrm{~N}_{4}$ to the $\mathrm{Cu}_{2} \mathrm{O}$ surface could form a conductive junction and induce effective electron transfer enforcing the Z-scheme process for $\mathrm{CO}_{2} \mathrm{RR}$ in high activity and selectivity. This result ensured the importance of junctions and interfaces in the hybrid catalyst structure to exhibit excellent photocatalytic $\mathrm{CO}_{2} \mathrm{RR}$ performances.

\section{Introduction}

Photocatalytic carbon dioxide reduction reaction $\left(\mathrm{CO}_{2} \mathrm{RR}\right)$ is one of the most straightforward approaches to converting carbon dioxide into synthetic fuels using solar energy ${ }^{1-5}$. It pursues reducing greenhouse gases and concomitantly storing renewable energy. Since Inoue et al. reported a pioneering work, photocatalytic $\mathrm{CO}_{2} \mathrm{RR}$ with heterogeneous catalysts have made impressive progress using various semiconductor materials ${ }^{5,6}$. As well as the electrochemical potentials $(E=-0.61 \sim-0.08 \mathrm{~V}$ vs. normal hydrogen electrode (NHE)) competitive to the hydrogen evolution reaction (HER), there exist multiple factors to be seriously considered, particularly for $\mathrm{CO}_{2} \mathrm{RR}$ : low $\mathrm{CO}_{2}$ adsorption on the catalyst surface, high overpotential required for the reaction, and low selectivity towards a single product. ${ }^{[6-12]}$

Metal oxides are suitable for photocatalytic $\mathrm{CO}_{2} \mathrm{RR}$ due to their affinity for $\mathrm{CO}_{2}$ coordination, generating stable intermediates. Among various oxides, copper(I) oxide, $\mathrm{Cu}_{2} \mathrm{O}$, is a suitable catalytic material with $\mathrm{p}$ type characteristics ${ }^{13}$. A narrow bandgap $(2.2 \mathrm{eV})$ leads to facile visible light absorption, and the high conduction band edge ( $-0.28 \mathrm{eV}$ vs. NHE) provides sufficient overpotentials yielding reduced products. However, the relatively high valence band edge ( $1.92 \mathrm{eV}$ vs. NHE) does not fit the oxidation potentials of counter-ions; therefore, heterojunction formation with n-type materials is a common strategy to promote both photoinduced electron and hole transfers to the reactants completing entire reaction circuits ${ }^{14} \cdot \mathrm{TiO}_{2}$ was combined with $\mathrm{Cu}_{2} \mathrm{O}$ and formed $p$-n junctions, resulting in a considerable enhancement of $\mathrm{CO}_{2} \mathrm{RR}^{15-}$ 17. We also generated a colloidal hybrid structure with p-type $\mathrm{ZnO}$, achieving a quantum efficiency of $1.5 \%$ with a nearly quantitative conversion into $\mathrm{CH}_{4}$ without sacrificial reagents ${ }^{18}$. Although these approaches have been successful on $\mathrm{CO}_{2} \mathrm{RR}$, the catalysts were highly sensitive to the reaction conditions, and the 
activity and stability were still limited. It may be caused by the instability of metal oxide surface and junctions; for example, $\mathrm{ZnO}$ is vulnerable under a low pH environment.

Recently, graphitic carbon nitrides, $\mathrm{g}-\mathrm{C}_{3} \mathrm{~N}_{4}$, have attracted much attention as photocatalysts due to their band gaps near the visible range $(2.7 \mathrm{eV})$ and high photochemical stability. Yet, g- $\mathrm{C}_{3} \mathrm{~N}_{4}$ alone has a low conduction band edge energy and induces fast charge-carrier recombination ${ }^{19-21}$. Hence, the hybridization with other semiconductors is a potential solution to overcome these problems. ${ }^{22}$ Several researchers have investigated the combination of $\mathrm{g}-\mathrm{C}_{3} \mathrm{~N}_{4}$ and $\mathrm{Cu}_{2} \mathrm{O}$ because their band energies match each other. However, the resulting materials were mainly used for dye decomposition but not for photocatalytic $\mathrm{CO}_{2} \mathrm{RR}^{23-27}$. In these reports, photoinduced excitons were proposed to transfer between distinct domains via the double charge transfer mechanism, making total band gaps narrower and providing potentials only to reduce organic dyes. For supplying sufficient overpotentials leading to $\mathrm{CO}_{2} \mathrm{RR}$, electron transfer between hetero-domains should occur via a Z-scheme pathway. Sun et al. prepared $\mathrm{Cu}_{2} \mathrm{O}$ particles on $\mathrm{g}-\mathrm{C}_{3} \mathrm{~N}_{4}$ foams and yielded $\mathrm{CO}$ in the gas phase reaction ${ }^{28}$. Zhao et al. encapsulated $\mathrm{Cu}_{2} \mathrm{O}$ nanowire arrays with $\mathrm{g}-\mathrm{C}_{3} \mathrm{~N}_{4}$, produced ethanol in the gas phase, and proposed the Zscheme mechanism by light irradiation ${ }^{29}$. These catalysts exhibited insufficient catalytic activities yet compared to other hybrid materials, despite the ideal band matching of $\mathrm{g}-\mathrm{C}_{3} \mathrm{~N}_{4}$ and $\mathrm{Cu}_{2} \mathrm{O}$.

In this work, we notice that uniform junctions and interfaces are critical to promoting effective charge transfer and separation in the hybrid structure. For this purpose, we induced the direct growth of $\mathrm{Cu}_{2} \mathrm{O}$ cubes on $\mathrm{g}-\mathrm{C}_{3} \mathrm{~N}_{4}$ sheets by a polyol process. The resulting g- $\mathrm{C}_{3} \mathrm{~N}_{4} / \mathrm{Cu}_{2} \mathrm{O}$ hybrid was used as a photocatalyst for $\mathrm{CO}_{2} \mathrm{RR}$ in an aqueous solution without sacrificial reagents. Remarkably, the catalyst exhibited an enormous activity of $5.4 \mathrm{mmol} \mathrm{g}_{\mathrm{cat}}{ }^{-1} \mathrm{~h}^{-1}$ and a quantum yield of $3.7 \%$, with a $\mathrm{CH}_{4}$ selectivity of $98 \%$. The measurements revealed that good electric junctions were formed between the $\mathrm{g}-\mathrm{C}_{3} \mathrm{~N}_{4}$ and $\mathrm{Cu}_{2} \mathrm{O}$ domains. The strong coupling through the interface may boost effective photo-induced electron transfer from g- $\mathrm{C}_{3} \mathrm{~N}_{4}$ to $\mathrm{Cu}_{2} \mathrm{O}$ via the Z-scheme process and provide a high potential enough to reduce $\mathrm{CO}_{2}$ into $\mathrm{CH}_{4}$ in a high efficiency.

\section{Results}

Hybrid formation and characterization. The $\mathrm{g}-\mathrm{C}_{3} \mathrm{~N}_{4} / \mathrm{Cu}_{2} \mathrm{O}$ hybrid was synthesized by the polyol process (Fig. 1a). In detail, g- $\mathrm{C}_{3} \mathrm{~N}_{4}$ nanosheets were prepared by urea pyrolysis at $550^{\circ} \mathrm{C}^{21}$. The transmission electron microscope (TEM) image shows crumbled g- $\mathrm{C}_{3} \mathrm{~N}_{4}$ sheets as nanosized fragments (Fig. $1 \mathrm{~b}$ ). The $\mathrm{g}-\mathrm{C}_{3} \mathrm{~N}_{4}$ sheets were transferred to 1,5-pentanediol in the presence of poly(vinyl pyrrolidone). The copper oxides were directly grown on the $\mathrm{g}-\mathrm{C}_{3} \mathrm{~N}_{4}$ surface by short heating after adding the copper precursor solution. The TEM image indicates that the nanocubes are formed with an average edge size of $25 \pm 8$ $\mathrm{nm}$, lying on the crumpled sheets (Fig. 1c and Supplementary Figs. S1 and S2). Notably, all cubes are attached to the sheets without free-standing particles under optimized synthetic conditions. 
A high-angle annular dark-field (HAADF) image and elemental mapping show that carbon and nitrogen are evenly distributed over the sheets. Copper is located at the positions the nanocubes exist (Supplementary Fig. S3). It reveals the formation of discernable $\mathrm{Cu}_{2} \mathrm{O}$ domains in the hybrid structure of g- $\mathrm{C}_{3} \mathrm{~N}_{4} / \mathrm{Cu}_{2} \mathrm{O}$. The high-resolution TEM (HRTEM) images (Fig. 1d and Supplementary Fig. S1) also represent two separate domains. The cube domain has lattice fringe images with average distances of 0.214 and $0.303 \mathrm{~nm}$ between neighboring fringes, assignable to the (200) and (110) planes of $\mathrm{Cu}_{2} \mathrm{O}$. The average distance of the adjacent fringes in the gray region is $0.336 \mathrm{~nm}$, corresponding to the (002) plane of $\mathrm{g}-\mathrm{C}_{3} \mathrm{~N}_{4}$.

The X-ray diffraction (XRD) pattern of $\mathrm{g}-\mathrm{C}_{3} \mathrm{~N}_{4} / \mathrm{Cu}_{2} \mathrm{O}$ is the sum of the (002) peak at $27^{\circ}$ from $\mathrm{g}-\mathrm{C}_{3} \mathrm{~N}_{4}$ (JCPDS No. 87-1526) and the (111) peak at $36^{\circ}$ from primitive cubic $\mathrm{Cu}_{2} \mathrm{O}$ (JCPDS No. 77-0199) (Fig. 2a). The UV-visible absorption spectrum of the hybrid (blue) is also the linear combination of $\mathrm{g}-\mathrm{C}_{3} \mathrm{~N}_{4}$ and $\mathrm{Cu}_{2} \mathrm{O}$; the high energy peaks are majorly from g- $\mathrm{C}_{3} \mathrm{~N}_{4}$ (red), and the tail up to $500 \mathrm{~nm}$ originates from $\mathrm{Cu}_{2} \mathrm{O}$ (black, Fig. 2b). X-ray photoelectron spectroscopy (XPS) provides essential information for bonding nature and oxidation states. Three species were analyzed by the deconvolution in the $\mathrm{C} 1 \mathrm{~s}$ region (Fig. 2c). The peak at $284.8 \mathrm{eV}$ (blue) is assignable to the adventitious carbon (C-C), and a shoulder (green) at $286.5 \mathrm{eV}$ and a large peak (red) at $288.1 \mathrm{eV}$ are ascribed as the carbons at $\mathrm{C}=\mathrm{N}$ and $\mathrm{N}-\mathrm{C}=\mathrm{N}$ bonds in the aromatic $\mathrm{CN}$ heterocycles, respectively. In the $\mathrm{N} 1 \mathrm{~s}$ region, the prominent peak (red) at $398.6 \mathrm{eV}$ and a broad peak (green) at $400.0 \mathrm{eV}$ correspond to the $\mathrm{N}$ atoms of $\mathrm{C}-\mathrm{N}=\mathrm{C}$ and tri-coordinate $\mathrm{N}-(\mathrm{C})_{3}$ bonds in the aromatic $\mathrm{CN}$ heterocycles. A shoulder at $401.1 \mathrm{eV}$ (blue) is assigned as the terminal amino group. These data present aromatic $\mathrm{CN}$ heterocycles with surface amino groups in the $\mathrm{g}-\mathrm{C}_{3} \mathrm{~N}_{4}$ sheets. A strong peak at $932.2 \mathrm{eV}$ in the $\mathrm{Cu} 2 \mathrm{p}_{3 / 2}$ region matches $\mathrm{Cu}(\mathrm{I})$ species of the $\mathrm{Cu}_{2} \mathrm{O}$ domains.

Photochemical $\mathrm{CO}_{2} \mathrm{RR}$ under aqueous medium. The $\mathrm{g}-\mathrm{C}_{3} \mathrm{~N}_{4} / \mathrm{Cu}_{2} \mathrm{O}$ hybrid was used as a photocatalyst for $\mathrm{CO}_{2} \mathrm{RR}$ under an aqueous medium without sacrificial reagents. After removing carbon residues to clean up the surface, the catalyst $(10 \mathrm{mg})$ was dispersed in a $\mathrm{CO}_{2}$-saturated buffer solution $(\mathrm{pH}=7.4)$. By irradiation using a $300 \mathrm{~W}$ Xe lamp, gas products were collected and analyzed by gas chromatography (GC). During the reaction up to $3 \mathrm{~h}$, the amount of $\mathrm{CH}_{4}$ linearly increased with the average activity of 53.6 $\mu \mathrm{mol} \mathrm{h}{ }^{-1}\left(5.4 \mathrm{mmol} \mathrm{g}_{\mathrm{cat}^{-1}} \mathrm{~h}^{-1}\right)$ with an exclusive selectivity (98\%) of $\mathrm{CH}_{4}$ (Fig. 3a). Quantum efficiency (QE) was calculated by the number of electrons used for $\mathrm{CH}_{4}$ evolution (eight electrons for producing each $\mathrm{CH}_{4}$ molecule from $\mathrm{CO}_{2}$ ) divided by the number of incident photons, estimated using the 200-540 nm absorption in the UV-visible spectrum ${ }^{30}$. In this experiment, the quantum efficiency was measured to be $3.7 \%$. The production amounts of $\mathrm{CO}$ and $\mathrm{H}_{2}$ were 4.8 and $1.4 \mu \mathrm{mol} \mathrm{h} \mathrm{h}^{-1}$, respectively (Fig. 3b), with no other liquid products detected by nuclear magnetic resonance (NMR) spectroscopy. $\mathrm{O}_{2}$ was evolved with the rate of $9.8 \mu \mathrm{mol} \mathrm{h} \mathrm{h}^{-1}$ by the counter oxidation reaction, far smaller than expected as a pair of $\mathrm{CO}_{2} \mathrm{RR}$. This stoichiometric unbalance has commonly been observed in photocatalytic reactions without sacrificial reagents or oxidation catalysts ${ }^{12,31}$. 
There have been numerous reports on photocatalytic $\mathrm{CO}_{2} \mathrm{RR}$, but the reaction conditions were so different that the reaction activities were hard to compare with each other. The reactions were either in $\mathrm{CO}_{2}$-saturated aqueous solutions or in the gas phase with $\mathrm{CO}_{2}$ and water vapor flow. In the aqueous solution, sacrificial hole acceptors were generally used to avoid the kinetic influence of counter-oxidation reactions, leading to the additional promotion of $\mathrm{CO}_{2} \mathrm{RR}$. We selected photocatalysts for $\mathrm{CO}_{2} \mathrm{RR}$ without using sacrificial reagents (Supplementary Table S1) ${ }^{32-39}$. The $\mathrm{g}-\mathrm{C}_{3} \mathrm{~N}_{4} / \mathrm{Cu}_{2} \mathrm{O}$ hybrid showed the largest QE with nearly quantitative conversion into $\mathrm{CH}_{4}$ among various heterogeneous photocatalysts reported thus far. Notably, the $\mathrm{g}-\mathrm{C}_{3} \mathrm{~N}_{4} / \mathrm{Cu}_{2} \mathrm{O}$ catalyst exhibited 2.5 times larger $\mathrm{QE}$ than the $\mathrm{ZnO}-\mathrm{Cu}_{2} \mathrm{O}$ colloidal catalyst (1.5\%) under identical reaction conditions for accurate comparison ${ }^{18}$.

The two hour-reaction was repeated three times using the same catalyst in a fresh $\mathrm{CO}_{2}$-saturated aqueous solution for the stability test. The average $\mathrm{CH}_{4}$ evolution rate was unchanged during the reaction cycles (Fig. 3c). After the three repetitive reactions, the XPS spectrum in the $\mathrm{Cu} 2 \mathrm{p}_{3 / 2}$ region did not significantly change the $\mathrm{Cu}(\mathrm{I})$ signal except for a slight increase of the $\mathrm{Cu}(\mathrm{II})$ peak intensity. The Auger peaks in the $\mathrm{Cu}$ LMM region were nearly identical before and after the catalytic cycles (Supplementary Fig. S4). The TEM images after the reaction show that the $\mathrm{Cu}_{2} \mathrm{O}$ domains retain an attachment with the g$\mathrm{C}_{3} \mathrm{~N}_{4}$ surface without damaging their cubic morphology (Supplementary Fig. S5).

We carried out a series of control experiments to ensure the photocatalytic $\mathrm{CO}_{2} \mathrm{RR}$ reaction (Supplementary Fig. S6): in the presence of the catalyst, no reaction progressed in the aqueous solution with $\mathrm{N}_{2}$ saturation; with the catalyst in the $\mathrm{CO}_{2}$-saturated solution, thermal energy without light irradiation could not proceed the reaction; without the catalyst, no conversion occurred by prolonged light irradiation to the $\mathrm{CO}_{2}$-saturated solution. We also performed the reaction with ${ }^{13} \mathrm{C}$-labeled $\mathrm{CO}_{2}$ to clarify the carbon source. During the experiment, the ${ }^{13} \mathrm{CH}_{4}$ signal intensity continuously grew in proportion to the irradiation time up to $6 \mathrm{~h}$ in the gas chromatography-mass spectrometry (GC-MS) analysis (Supplementary Fig. S7).

These superior features of the catalysts for $\mathrm{CO}_{2} \mathrm{RR}$ are ascribed to the strong coupling of two distinct domains by heterojunction formation. When each domain was solely used for the reaction under the identical reaction conditions, the $\mathrm{CH}_{4}$ production rates were as low as $1.7 \mu \mathrm{mol} \mathrm{h}{ }^{-1}$ for the $\mathrm{g}^{-} \mathrm{C}_{3} \mathrm{~N}_{4}$ sheets and $3.1 \mu \mathrm{mol} \mathrm{h}^{-1}$ for the $\mathrm{Cu}_{2} \mathrm{O}$ nanocubes, respectively. On the contrary, $\mathrm{g}-\mathrm{C}_{3} \mathrm{~N}_{4} / \mathrm{Cu}_{2} \mathrm{O}$ produced an 18 times larger amount of $\mathrm{CH}_{4}$ than each material (Fig. 3d). Interestingly, a physical mixture of the two materials exhibited an activity of $0.089 \mu \mathrm{mol} \mathrm{h}^{-1}$, even lower than that with the $\mathrm{Cu}_{2} \mathrm{O}$ nanocubes only. The photoinduced electrons in the $\mathrm{Cu}_{2} \mathrm{O}$ cubes may be consumed by the $\mathrm{g}-\mathrm{C}_{3} \mathrm{~N}_{4}$ sheets through collision, which would prevent the direct electron transfer to $\mathrm{CO}_{2}$.

In the UV-visible spectrum (Fig. 2b), the absorption tail is extended to the visible region, although most of the absorption occurs in the UV region below $400 \mathrm{~nm}$. The visible activity of the catalyst was measured by light irradiation using a filter cutting off the wavelengths shorter than $420 \mathrm{~nm}$ (Supplementary Fig. S8). 
$\mathrm{CH}_{4}$ was still a primary product with a rate of $1.9 \mu \mathrm{mol} \mathrm{h} \mathrm{h}^{-1}$ and a selectivity of $95 \%$. The g- $\mathrm{C}_{3} \mathrm{~N}_{4}$ domains have relatively low absorption in the visible region, which significantly affects the $\mathrm{CO}_{2} \mathrm{RR}$ activity.

Reaction pathways through heterojunctions. The origin of superior activity for $\mathrm{CH}_{4}$ production in the g$\mathrm{C}_{3} \mathrm{~N}_{4} / \mathrm{Cu}_{2} \mathrm{O}$ catalyst was examined in detail. The estimated band diagram of the heterojunction catalyst is depicted with corresponding potentials vs. NHE (Fig. 4a). The band gaps were estimated to be $2.8 \mathrm{eV}$ for $\mathrm{g}-\mathrm{C}_{3} \mathrm{~N}_{4}$ and $2.2 \mathrm{eV}$ for $\mathrm{Cu}_{2} \mathrm{O}$, respectively, by the Tauc plots based on the UV-visible absorption spectra (Fig. $2 \mathrm{~b}$ and Supplementary Fig. S9) ${ }^{40}$. Band edge potentials were calculated from the Mott-Schottky plots of $\mathrm{g}-\mathrm{C}_{3} \mathrm{~N}_{4}$ and g- $\mathrm{C}_{3} \mathrm{~N}_{4} / \mathrm{Cu}_{2} \mathrm{O}$ at 1200 and $2700 \mathrm{~Hz}^{41}$.

For the heterojunction materials, two opposite mechanisms have been proposed: double charge transfer and Z-scheme ${ }^{1,42}$. In the Z-scheme mechanism, photoinduced electrons at the conduction band edge of the $\mathrm{g}-\mathrm{C}_{3} \mathrm{~N}_{4}$ domain migrate into the valence band edge of the $\mathrm{Cu}_{2} \mathrm{O}$ domain through the interface. As a result, long-lived charge-separated states can be generated; the excited electrons at the conduction band of the $\mathrm{Cu}_{2} \mathrm{O}$ reduce surface-adsorbed $\mathrm{CO}_{2}$, and the holes at the valence band of the $\mathrm{g}-\mathrm{C}_{3} \mathrm{~N}_{4}$ oxidize water to $\mathrm{O}_{2}{ }^{42-44}$. Due to the large energy gap between the photoinduced electrons and holes, $\mathrm{CO}_{2} \mathrm{RR}$ and water oxidation gain overpotentials sufficient for proceeding with the reactions. Note that $\mathrm{Cu}_{2} \mathrm{O}$ solely cannot lead to water oxidation under the present reaction conditions.

We performed several experiments to evidence the Z-scheme process as a dominant reaction pathway of the $\mathrm{g}-\mathrm{C}_{3} \mathrm{~N}_{4} / \mathrm{Cu}_{2} \mathrm{O}$ catalyst. Photoresponses were measured using the catalyst deposited on the fluorinedoped tin oxide (FTO) electrode at $-0.25 \mathrm{~V} \mathrm{vs}$. $\mathrm{Ag} / \mathrm{AgCl}$ in a phosphate buffer. The photocurrent density of the hybrid catalyst (red) was measured to be $32.8 \mu \mathrm{A} \mathrm{cm}{ }^{-2}$ by irradiation, which was three times higher than that of the $\mathrm{g}_{3} \mathrm{C}_{4} \mathrm{~N}_{4}\left(11.1 \mu \mathrm{A} \mathrm{cm}{ }^{-2}\right.$, black) (Fig. $\left.4 \mathrm{~b}\right)$. It reveals that the photoinduced charge separation occurs more efficiently in the hybrid structure. The visible light irradiation induced an even significant photocurrent difference from $\mathrm{g}-\mathrm{C}_{3} \mathrm{~N}_{4}$, indicating that the charge separation relies on the bandgap of the $\mathrm{Cu}_{2} \mathrm{O}$ domain (Supplementary Fig. S10). For the direct comparison, the photoresponse of the $\mathrm{ZnO}-\mathrm{Cu}_{2} \mathrm{O}$ catalyst was measured under identical circumstances ${ }^{18}$. The photocurrent of $\mathrm{g}-\mathrm{C}_{3} \mathrm{~N}_{4} / \mathrm{Cu}_{2} \mathrm{O}$ was two times larger than that of $\left.\mathrm{ZnO}^{-\mathrm{Cu}_{2} \mathrm{O}(14.6 \mu \mathrm{A} \mathrm{cm}}{ }^{-2}\right)$, proving the better performances caused by effective charge separation on the proper catalyst combination (Supplementary Fig. S11).

It is known that the interface between the two domains should form an Ohmic contact with low contact resistance for inducing the Z-scheme-type electron transfer ${ }^{42}$. We suggest that such good electric contact is the main reason for the high $\mathrm{CO}_{2} \mathrm{RR}$ activity, as well as matching band positions of the distinct domains. The photoluminescence $(\mathrm{PL})$ spectrum of $\mathrm{g}-\mathrm{C}_{3} \mathrm{~N}_{4}$ by excitation with $375 \mathrm{~nm}$ light shows a prominent peak with a maximum at $435 \mathrm{~nm}$ (Fig. $4 \mathrm{c}$ ). The $\mathrm{PL}$ intensity of g- $\mathrm{C}_{3} \mathrm{~N}_{4} / \mathrm{Cu}_{2} \mathrm{O}$ is ten times weaker than that of $\mathrm{g}-\mathrm{C}_{3} \mathrm{~N}_{4}$, indicating that the excited electrons at the conduction band of $\mathrm{g}-\mathrm{C}_{3} \mathrm{~N}_{4}$ migrate into the other energy levels; i. e., the valence band of $\mathrm{Cu}_{2} \mathrm{O}$. We also examined photoexcited carrier dynamics by time-correlated single-photon counting (TCSPC) (Fig. 4d). The overall exciton lifetimes were 
estimated by the amplitude-weighted average of the triexponential decay functions (Supplementary Table S2). The lifetimes were $2.9 \mathrm{~ns}$ for $\mathrm{g}-\mathrm{C}_{3} \mathrm{~N}_{4}$ and $1.9 \mathrm{~ns}$ for $\mathrm{g}-\mathrm{C}_{3} \mathrm{~N}_{4} / \mathrm{Cu}_{2} \mathrm{O}$, respectively. This lifetime decrease in the hybrid catalyst means the rapid transfer of photoexcited electrons from the $\mathrm{g}-\mathrm{C}_{3} \mathrm{~N}_{4}$ to the $\mathrm{Cu}_{2} \mathrm{O}$ domains through the heterojunction ${ }^{28,45}$.

Electrochemical impedance spectroscopy (EIS) analysis provides additional evidence of the charge transfer behavior ${ }^{26,46}$. The semi-arc loops appear in the middle frequency region in the Nyquist plots. The arc diameters are assigned as the charge transfer resistance - the sum of the electrolyte resistance on the electrodes, the electrode resistance, and the contact resistance with the current collector. In our experiments, the electrolyte and contact resistances are expected to be close due to the structural similarity of $\mathrm{g}-\mathrm{C}_{3} \mathrm{~N}_{4}$ and $\mathrm{g}-\mathrm{C}_{3} \mathrm{~N}_{4} / \mathrm{Cu}_{2} \mathrm{O}$ deposited on the electrodes by the same treatment; then, the measured resistance would be directly related to the charge transfer in the catalyst material. The charge transfer resistances were estimated to be $369.5 \Omega$ for g- $\mathrm{C}_{3} \mathrm{~N}_{4}$ and $171.0 \Omega$ for g- $\mathrm{C}_{3} \mathrm{~N}_{4} / \mathrm{Cu}_{2} \mathrm{O}$, indicating rapid interfacial charge separation and transfer in the $\mathrm{g}-\mathrm{C}_{3} \mathrm{~N}_{4} / \mathrm{Cu}_{2} \mathrm{O}$ hybrid structure (Fig. 4e). These photophysical and electrochemical properties univocally represent the facile photoinduced electron transfer from the $\mathrm{g}-\mathrm{C}_{3} \mathrm{~N}_{4}$ to the $\mathrm{Cu}_{2} \mathrm{O}$ domains on $\mathrm{g}-\mathrm{C}_{3} \mathrm{~N}_{4} / \mathrm{Cu}_{2} \mathrm{O}$, resulting in enforcing the Z-scheme process for $\mathrm{CO}_{2} \mathrm{RR}$.

We suppose that this effective photoinduced electron transfer is ascribed to the strong interaction between the hetero-domains induced by growing $\mathrm{Cu}$ domains directly on the defect sites of $\mathrm{g}-\mathrm{C}_{3} \mathrm{~N}_{4}$. X-ray absorption near-edge spectroscopy (XANES) was performed to identify the species and their electronic properties. The $\mathrm{Cu}$ K-edge spectrum of $\mathrm{g}-\mathrm{C}_{3} \mathrm{~N}_{4} / \mathrm{Cu}_{2} \mathrm{O}$ (red) shows a distinctive shoulder at $8983.4 \mathrm{eV}$ attributed to the $1 \mathrm{~s}$ to $3 \mathrm{~d}$ transition and a strong absorption edge at $8996.5 \mathrm{eV}$ for the $1 \mathrm{~s}$ to $4 \mathrm{p}$ transition (Fig. 4f). The two edges shift to the high energy by 0.8 and $1.6 \mathrm{eV}$, compared to the absorption edges of the $\mathrm{Cu}_{2} \mathrm{O}$ standard (blue). These positive shifts were similarly observed in single $\mathrm{Cu}$ atoms deposited on carbon nitrides, indicating that the strong $\mathrm{N}$-coordination on the $\mathrm{Cu}$ surface is present at the interface between the two domains ${ }^{47}$. The $\mathrm{Cu}-\mathrm{N}$ bonding is likely to form at the early stage of the polyol synthesis. The $\mathrm{Cu}(\mathrm{I})$ atoms reduced from the copper precursor can be bound on the $\mathrm{N}$ atoms at the defects of $\mathrm{g}$ $\mathrm{C}_{3} \mathrm{~N}_{4}$, and direct and continuous $\mathrm{Cu}$ deposition on these sites leads to growing single-crystalline $\mathrm{Cu}_{2} \mathrm{O}$ domains. As a result, a large number of $\mathrm{Cu}-\mathrm{N}$ bonding with the defect sites generates quasi-continuous energy levels at the contact interface. This situation is like the conductors, ready to form the Ohmic contact promoting the electron transfer between the two domains, enforcing the Z-scheme process, and inducing the stable charge-separated states ${ }^{47-49}$.

\section{Discussion}

In conclusion, we induced the direct growth of $\mathrm{Cu}_{2} \mathrm{O}$ nanocubes on $\mathrm{g}-\mathrm{C}_{3} \mathrm{~N}_{4}$ sheets by a polyol process. The resulting g- $\mathrm{C}_{3} \mathrm{~N}_{4} / \mathrm{Cu}_{2} \mathrm{O}$ hybrid formed good electric junctions between the two distinct domains. The hybrid was employed as a photocatalyst for $\mathrm{CO}_{2} \mathrm{RR}$ in an aqueous solution. They exhibited enormous 
activity of $5.4 \mathrm{mmol} \mathrm{g}_{\mathrm{cat}}{ }^{-1} \mathrm{~h}^{-1}$ with a quantum yield of $3.7 \%$ and a selectivity of $98 \%$ for $\mathrm{CH}_{4}$ production. To the best of our knowledge, $\mathrm{g}-\mathrm{C}_{3} \mathrm{~N}_{4} / \mathrm{Cu}_{2} \mathrm{O}$ is one of the most active photocatalysts among any other catalytic materials for $\mathrm{CO}_{2} \mathrm{RR}$ in aqueous media without sacrificial reagents. The catalyst was recyclable three times without changing the catalyst morphology. The photocatalytic reaction mechanism was rationalized as the Z-scheme process. The direct growth of $\mathrm{Cu}$ on $\mathrm{g}-\mathrm{C}_{3} \mathrm{~N}_{4}$ led to the strong coordination of $\mathrm{g}-\mathrm{C}_{3} \mathrm{~N}_{4}$ to the $\mathrm{Cu}_{2} \mathrm{O}$ domains, which formed conductive junctions to promote the facile electron transfer from g- $\mathrm{C}_{3} \mathrm{~N}_{4}$ to $\mathrm{Cu}_{2} \mathrm{O}$ following the Z-scheme, and provided sufficient overpotentials for $\mathrm{CO}_{2} \mathrm{RR}$. It reveals that the primary keys of hybrid photocatalyst design toward high-performance $\mathrm{CO}_{2} \mathrm{RR}$ are: 1) matching band positions and 2) generating good ohmic junctions between two distinct materials. This work reconfirms basic principles to fabricate high performance photocatalysts bearing a general form of catalyst-cocatalyst combinations.

\section{Methods}

Chemicals. Urea (99.0\%, Sigma-Aldrich), 1,5-pentanediol (1,5-PD, 96\%, Sigma-Aldrich), poly(vinyl pyrrolidone) (PVP, $\mathrm{M}_{\mathrm{w}}=55,000$, Sigma-Aldrich), copper(II) acetylacetonate (Cu(acac) 2 , $\geq 99.95 \%$, SigmaAldrich), and ethanol (99.5\%. Daejung) were used as received. Deionized water was used throughout all experiments.

Synthesis of $\mathbf{g}-\mathrm{C}_{3} \mathrm{~N}_{\mathbf{4}}$ nanosheets. $5.0 \mathrm{~g}$ of urea was placed in a semi-closed quartz reactor with fiber glasses. The reactor was heated to $550^{\circ} \mathrm{C}$ for $2 \mathrm{~h}$ under static air in a furnace with a ramping rate of $5{ }^{\circ} \mathrm{C}$ $\mathrm{min}^{-1}$. After the reaction, the reactor was cooled to room temperature. The resulting light-yellow product was thoroughly washed with ethanol and water.

Synthesis of $\mathrm{g}-\mathrm{C}_{3} \mathrm{~N}_{4} / \mathrm{Cu}_{2} \mathrm{O}$ hybrid catalysts. The solution comprising g- $\mathrm{C}_{3} \mathrm{~N}_{4}(0.015 \mathrm{~g})$, PVP (1.5 g, 12.0 $\mathrm{mmol})$, and 1,5-PD (50 mL) was heated to $130{ }^{\circ} \mathrm{C}$ under inert conditions. The mixture was heated to 225 ${ }^{\circ} \mathrm{C}$. Subsequently, a solution of copper acetylacetonate $(0.040 \mathrm{~g}, 0.16 \mathrm{mmol})$ and 1,5-PD $(5.0 \mathrm{~mL})$ was added and stirred at the same temperature. After $5 \mathrm{~min}$, the reaction mixture was cooled to room temperature, yielding g- $\mathrm{C}_{3} \mathrm{~N}_{4} / \mathrm{Cu}_{2} \mathrm{O}$ hybrid catalysts. The resulting light orange product was thoroughly washed with ethanol.

Materials Characterization. TEM and HRTEM images were obtained by using an FEl Tecnai G2 F20 (200 kV). STEM and EDS elemental mapping images were obtained in Talos F200X (200 kV). The specimens were prepared by dropping a few samples dispersed in ethanol on carbon-coated 200-mesh nickel grids (Ted Pella Inc.). XRD patterns were recorded on a Rigaku D/MAX-2500 diffractometer. XPS was obtained 
by K-alpha X-ray photoelectron spectroscopy (Thermo VG Scientific). UV-visible absorption spectra were measured from Shimadzu UV-3600 spectrophotometer at room temperature. Steady-state photoluminescence (PL) spectra were obtained from a spectrophotometer (F-7000, Hitachi) at room temperature. Time-resolved photoluminescence $(\mathrm{PL})$ spectra were obtained from a spectrophotometer (Fluotime 300, PicoQuant) with picosecond-pulsed diode lasers (output wavelengths of $375 \mathrm{~nm}$ ) at room temperature.

X-ray absorption spectroscopy analysis. X-ray absorption fine spectroscopy (XAFS) of hybrid catalysts over Cu K-edge, 8979 eV in copper foil was analyzed at Pohang Accelerator Laboratory (7D-XAFS beamline in PLS-II) using $\mathrm{Si}(111)$ crystal as a monochromator where the beam energy and ring current were $2.5 \mathrm{GeV}$ and $300 \mathrm{~mA}$, respectively. The step and duration times for X-ray absorption near edge structure (XANES) and extended X-ray absorption fine structure (EXAFS) were $0.40 \mathrm{eV}$ and $2.0 \mathrm{~s}$, and 0.30 $\mathrm{nm}^{-1}$ and $3.0 \mathrm{~s}$, respectively. Athena implemented in Demeter program package (0.9.25) was used for date producing and background removal to extract XAFS signal using AUTOBK program for Rbkg $=0.1 \mathrm{~nm}$. Corresponding XAFS data in k-space was Fourier transformed with the Kaiser-Bessel window function after $\mathrm{k}^{2}$ - or $\mathrm{k}^{3}$ - weighting to amplify the high range of $\mathrm{k}$ information. The range for Fourier transformation of Cu samples, $\Delta \mathrm{k}$ was $30 \sim 130 \mathrm{~nm}^{-1}$ or $3 \sim 13 \AA^{-1}$. The phase shifts and amplitude functions of the reference were generated using Feff $6 \mathrm{~L}$. The curve fitting range in $r$ space, $\Delta r$, was varied depending on the sample. The number of independent points of the data for the curve fit, Nidp determined from the Nyquist theorem was always larger than the number of variables, providing a sufficient degree of freedom, $\mathrm{N}_{\mathrm{var}}$. The scattering path from the possible model structure was obtained from the Feff calculation. Reduction factor, $\mathrm{S} 02$ for $\mathrm{Cu}, 0.85$ was obtained from the curve fit of the XAFS data of Cu foil under the same condition and utilized further in the curve fit of the sample. The statistical quality of the curve fit or proposed model was determined from the R-factor available in the refinement.

Photocatalytic $\mathrm{CO}_{2}$ conversion experiments. Before photocatalytic measurements, g- $\mathrm{C}_{3} \mathrm{~N}_{4} / \mathrm{Cu}_{2} \mathrm{O}$ hybrid catalysts were thoroughly washed with ethanol and water to remove carbon residues. Then, $10 \mathrm{mg}$ of $\mathrm{g}$ $\mathrm{C}_{3} \mathrm{~N}_{4} / \mathrm{Cu}_{2} \mathrm{O}$ hybrid catalysts were dispersed in water $(80 \mathrm{~mL})$. The reactor was a homemade quartz flask with a total volume of $215 \mathrm{~mL}$. Supercritical-fluid grade $\mathrm{CO}_{2}$ gas was used to avoid any hydrocarbon contamination. To make the $\mathrm{CO}_{2}$ saturation in the reaction medium, $\mathrm{CO}_{2}$ gas was additionally bubbled at ambient pressure and temperature for $30 \mathrm{~min}$. The photocatalytic $\mathrm{CO}_{2}$ conversion was conducted by irradiation using a Xe lamp (300 W, Oriel) equipped with a $10 \mathrm{~cm}$ IR water filter. During the reaction, the gas product was collected using a needle-type probe passing through a sealed rubber septum. The gas sample was analyzed by an FID detector equipped with a Carboxen 1000 column in gas chromatography. 
Mott-Schottky plot measurements. The flat-band edge positions of g- $\mathrm{C}_{3} \mathrm{~N}_{4}$ and g- $\mathrm{C}_{3} \mathrm{~N}_{4} / \mathrm{Cu}_{2} \mathrm{O}$ were measured by electrochemical impedance measurement. The working electrode was made by coating catalysts on fluorine-doped tin oxide (FTO) conducting glasses with an area of $0.50 \mathrm{~cm}^{2}$. The $0.40 \mathrm{M}$ $\mathrm{Na}_{2} \mathrm{SO}_{4}$ solution ( $\mathrm{pH}$ 6.8) was used as an electrolyte, a platinum wire was used as a counter electrode, and $\mathrm{Ag} / \mathrm{AgCl}$ (in $3.0 \mathrm{M} \mathrm{NaCl}$ solution) was used as a reference electrode. Electrochemical impedance spectroscopy (EIS) measurement was carried out by using a $\mathrm{CH}$ instruments Electrochemical Workstation and the potential was scanned with the step of $0.05 \mathrm{~V}$ with $5 \mathrm{~Hz}$ frequency. Potential conversion between $\mathrm{Ag} / \mathrm{AgCl}$ and $\mathrm{NHE}$ was given by $\mathrm{E}(\mathrm{NHE})=\mathrm{E}(\mathrm{Ag} / \mathrm{AgCl})+0.212 \mathrm{~V}$.

Photocurrent measurements. The photocurrent responses were measured on DY2321 potentiostat (DigiIvy). The working electrode was made by coating catalysts on fluorine-doped tin oxide (FTO) conducting glasses with an area of $0.50 \mathrm{~cm}^{2}$. The $0.10 \mathrm{M}$ Phosphate buffer solution $(\mathrm{pH} 7.4)$ was used as an electrolyte, a platinum wire was used as a counter electrode, and $\mathrm{Ag} / \mathrm{AgCl}$ (in $1.0 \mathrm{M} \mathrm{KCl}$ solution) was used as a reference electrode. $150 \mathrm{~W}$ Xe lamp (Abet Technologies) was used as a light source for photocurrent measurement. The lamp intensity on the sample was measured to be $100 \mathrm{~mW} \mathrm{~cm}{ }^{-2}$.

Quantum efficiency calculation. The apparent quantum efficiency was calculated by a method reported by Bharadwaj et al. ${ }^{30}$ First, the incident light power was measured using the power meter (Newport 848$\mathrm{R})$, assuming that the light intensity was uniformly distributed. Second, the emission profile of the $\mathrm{Xe}$ lamp was recorded by using a fiber-coupled spectrometer (Ocean Optics USB4000) in the range of 200$700 \mathrm{~nm}$. Third, based on UV-visible absorption spectrum data, the effective absorption for the photocatalytic reaction was assumed in the range of 200-520 $\mathrm{nm}$. The light power $\left(E_{m}\right)$ in the range of 200-520 nm was calculated by multiplying the total light power $(200-700 \mathrm{~nm})$ with the fraction of the area $(200-520 \mathrm{~nm})$ to the total area $(200-700 \mathrm{~nm})$ in the emission spectrum. The energy of a single photon was considered to be the weighted average energy of all photons in the range of $200-520 \mathrm{~nm}$. For this, contribution of a photon of each wavelength $(200-520 \mathrm{~nm})$ towards the total energy was calculated as

$$
E_{i}\left(\lambda_{i}\right)=\frac{I_{\lambda i}}{I_{\text {total }}} \times \frac{h c}{\lambda_{i}}
$$

where $I_{\lambda i}$ is the intensity at wavelength $\lambda_{i}$, and $I_{\text {total }}$ is the sum of intensities of all photons in the wavelength range of 200 to $520 \mathrm{~nm}$ obtained from the emission profile of the lamp. The weighted average energy of single-photon $\left(E_{a}\right)$ is calculated as

$$
E_{a}=\sum_{\lambda_{i}=200}^{520} \mathrm{E}_{i}\left(\lambda_{i}\right)
$$


The total number of incident photons in the $200-520 \mathrm{~nm}$ range $(\mathrm{N})$ is finally calculated by

$$
N=\frac{E_{m}}{E_{a}}
$$

\section{Declarations}

\section{Acknowledgements}

This work was supported by the Saudi-Aramco and $\mathrm{KAIST} \mathrm{CO}_{2}$ management center. This work was also supported by the National Research Foundation of Korea (NRF), funded by the Korea Government (MSIP) (NRF-2018R1A2B3004096, NRF-2018R1A5A1025208). The authors acknowledge the Pohang Accelerator Laboratory (PAL) for beamline use. EXAFS experiments at PLS were supported by MSIP and POSTECH.

\section{Author Contributions}

B.C. and C.K.L. contributed equally to this work. B.C., C.K.L., and H.S. designed experiments. M.K. carried out X-ray absorption spectroscopy analysis. B.P. and W.-W.P. performed photocurrent and photoluminescence measurements. B.C., C.K.L., O.-H.K., H.-S.L., and H.S. contributed to writing the paper.

\section{Competing interests}

The authors declare no competing interests.

\section{Additional Information}

Supplementary information The online version contains supplementary material available at https://doi.org/xx.xxxx/xxxxx.

Correspondence and requests for materials should be addressed to Hyunjoon Song.

\section{References}

1. Roy, S. C., Varghese, O. K., Paulose, M. \& Grimes, C. A. Toward solar fuels: photocatalytic conversion of carbon dioxide to hydrocarbons. ACS Nano 4, 1259-1278 (2010). 
2. Chang, X., Wang, T. \& Gong, J. $\mathrm{CO}_{2}$ photo-reduction: insights into $\mathrm{CO}_{2}$ activation and reaction on surfaces of photocatalysts. Energy Environ. Sci. 9, 2177-2196 (2016).

3. White, J. L. et al. Light-driven heterogeneous reduction of carbon dioxide: photocatalysts and photoelectrodes. Chem. Rev. 115, 12888-12935 (2015).

4. Lingampalli, S. R., Ayyub, M. M. \& Rao, C. N. R. Recent progress in the photocatalytic reduction of carbon dioxide. ACS Omega 2, 2740-2748 (2017).

5. Inoue, T., Fujishima, A., Konishi, S. \& Honda, K. Photoelectrocatalytic reduction of carbon dioxide in aqueous suspensions of semiconductor powders. Nature 277, 637-638 (1979).

6. Habisreutinger, S. N., Schmidt-Mende, L. \& Stolarczyk, J. K. Photocatalytic reduction of $\mathrm{CO}_{2}$ on $\mathrm{TiO}_{2}$ and other semiconductors. Angew. Chem. Int. Ed. 52, 7372-7408 (2013).

7. Linsebigler, A. L.; Lu, G.; Yates, J. T. Photocatalysis on $\mathrm{TiO}_{2}$ surfaces: principles, mechanisms, and selected results. Chem. Rev. 95, 735-758 (1995).

8. Wang, W.-N. et al. Size and structure matter: enhanced $\mathrm{CO}_{2}$ photoreduction efficiency by size-resolved ultrafine Pt nanoparticles on $\mathrm{TiO}_{2}$ single crystals. J. Am. Chem. Soc. 134, 11276-11281 (2012).

9. Liu, Q. et al. High-yield synthesis of ultralong and ultrathin $\mathrm{Zn}_{2} \mathrm{GeO}_{4}$ nanoribbons toward improved photocatalytic reduction of $\mathrm{CO}_{2}$ into renewable hydrocarbon fuel. J. Am. Chem. Soc. 132, 1438514387 (2010).

10. Zhai, Q. et al. Photocatalytic conversion of carbon dioxide with water into methane: platinum and copper (I) oxide co-catalysts with a core-shell structure. Angew. Chem. Int. Ed. 125, 5776-5779 (2013).

11. Xing, M. et al. Modulation of the reduction potential of $\mathrm{TiO}_{2-x}$ by fluorination for efficient and selective $\mathrm{CH}_{4}$ generation from $\mathrm{CO}_{2}$ photoreduction. Nano Lett. 18, 3384-3390 (2018).

12. Choi, J. Y. et al. Surface activation of cobalt oxide nanoparticles for photocatalytic carbon dioxide reduction to methane. J. Mater. Chem. A 7, 15068-15072 (2019).

13. Sun, $\mathrm{S}$. Recent advances in hybrid $\mathrm{Cu}_{2} \mathrm{O}$-based heterogeneous nanostructures. Nanoscale 7, 1085010882 (2015).

14. Prabhu, P., Jose, V. \& Lee, J. M. Heterostructured catalysts for electrocatalytic and photocatalytic carbon dioxide reduction. Adv. Funct. Mater. 30, 1910768 (2020).

15. Aguirre, M. E., Zhou, R., Eugene, A. J., Guzman, M. I. \& Grela, M. A. $\mathrm{Cu}_{2} \mathrm{O} / \mathrm{TiO}_{2}$ heterostructures for $\mathrm{CO}_{2}$ reduction through a direct Z-scheme: Protecting $\mathrm{Cu}_{2} \mathrm{O}$ from photocorrosion. Appl. Catal. B 217, 485493 (2017).

16. Wang, J., Ji, G., Liu, Y., Gondal, M. \& Chang, X. $\mathrm{Cu}_{2} \mathrm{O} / \mathrm{TiO}_{2}$ heterostructure nanotube arrays prepared by an electrodeposition method exhibiting enhanced photocatalytic activity for $\mathrm{CO}_{2}$ reduction to methanol. Catal. Commun. 46, 17-21 (2014).

17. Jeong, $\mathrm{S}$. et al. Selectivity modulated by surface ligands on $\mathrm{Cu}_{2} \mathrm{O} / \mathrm{TiO}_{2}$ catalysts for gas-phase photocatalytic reduction of carbon dioxide. J. Phys. Chem. C123, 29184-29191 (2019). 
18. Bae, K.-L., Kim, J., Lim, C. K., Nam, K. M. \& Song, H. Colloidal zinc oxide-copper(I) oxide nanocatalysts for selective aqueous photocatalytic carbon dioxide conversion into methane. Nat. Commun. 8, 1156 (2017).

19. Wen, J., Xie, J., Chen, X. \& Li, X. A review on g- $\mathrm{C}_{3} \mathrm{~N}_{4}$-based photocatalysts. Appl. Surf. Sci. 391, 72123 (2017).

20. Zheng, Y., Liu, J., Liang, J., Jaroniec, M. \& Qiao, S. Z. Graphitic carbon nitride materials: controllable synthesis and applications in fuel cells and photocatalysis. Energy Environ. Sci. 5, 6717-6731 (2012).

21. Majdoub, M., Anfar, Z. \& Amedlous, A. Emerging chemical functionalization of $\mathrm{g}-\mathrm{C}_{3} \mathrm{~N}_{4}$ : covalent/noncovalent modifications and applications. ACS Nano 14, 12390-12469 (2020).

22. Masih, D., Ma, Y. \& Rohani, S. Graphitic $\mathrm{C}_{3} \mathrm{~N}_{4}$ based noble-metal-free photocatalyst systems: a review. Appl. Catal. B 206, 556-588 (2017).

23. Li, A. et al. Adjusting the reduction potential of electrons by quantum confinement for selective photoreduction of $\mathrm{CO}_{2}$ to methanol. Angew. Chem. Int. Ed. 58, 3804-3808 (2019).

24. Li, D. et al. Synthesis of a g- $\mathrm{C}_{3} \mathrm{~N}_{4}-\mathrm{Cu}_{2} \mathrm{O}$ heterojunction with enhanced visible light photocatalytic activity by PEG. J. Colloid Interface Sci. 531, 28-36 (2018).

25. Surikanti, G. R., Bajaj, P. \& Sunkara, M. V. g- $\mathrm{C}_{3} \mathrm{~N}_{4}$-mediated synthesis of $\mathrm{Cu}_{2} \mathrm{O}$ To obtain porous composites with improved visible light photocatalytic degradation of organic dyes. ACS Omega 4, $17301-17316$ (2019).

26. Si, Y. et al. Facile in-situ synthesis of $2 \mathrm{D} / 3 \mathrm{D} \mathrm{g}-\mathrm{C}_{3} \mathrm{~N}_{4} / \mathrm{Cu}_{2} \mathrm{O}$ heterojunction for high-performance photocatalytic dye degradation. Mater. Res. Express 7, 015524 (2020).

27. Liu, B., Wu, Y., Zhang, J., Han, X. \& Shi, H. Visible-light-driven g- $\mathrm{C}_{3} \mathrm{~N}_{4} / \mathrm{Cu}_{2} \mathrm{O}$ heterostructures with efficient photocatalytic activities for tetracycline degradation and microbial inactivation. J. Photochem. Photobiol. A 378, 1-8 (2019).

28. Sun, Z. et al. $\mathrm{g}-\mathrm{C}_{3} \mathrm{~N}_{4}$ foam/ $\mathrm{Cu}_{2} \mathrm{O}$ QDs with excellent $\mathrm{CO}_{2}$ adsorption and synergistic catalytic effect for photocatalytic $\mathrm{CO}_{2}$ reduction. Environ. Int. 130, 104898 (2019).

29. Zhao, X. et al. Nanoengineering construction of $\mathrm{Cu}_{2} \mathrm{O}$ nanowire arrays encapsulated with g- $\mathrm{C}_{3} \mathrm{~N}_{4}$ as 3D spatial reticulation all-solid-state direct Z-scheme photocatalysts for photocatalytic reduction of carbon dioxide. ACS Catal. 10, 6367-6376 (2020).

30. Sasikala, R. et al. Enhanced photocatalytic hydrogen evolution over nanometer sized Sn and Eu doped titanium oxide. Int. J. Hydrog. Energy 33, 4966-4973 (2008).

31. Varghese, O. K., Paulose, M., LaTempa, T. J. \& Grimes, C. A. High-rate solar photocatalytic conversion of $\mathrm{CO}_{2}$ and water vapor to hydrocarbon fuels. Nano Lett. 9, 731-737 (2009).

32. Wang, F. et al. Ordered macroporous carbonous frameworks implanted with CdS quantum dots for efficient photocatalytic $\mathrm{CO}_{2}$ reduction. Adv. Mater. 33, 2102690 (2021). 
33. $\mathrm{Di}, \mathrm{J}$. et al. Cobalt nitride as a novel cocatalyst to boost photocatalytic $\mathrm{CO}_{2}$ reduction. Nano Energy 79, 105429 (2021).

34. $\mathrm{Di}, \mathrm{J}$. et al. Defect-rich $\mathrm{Bi}_{12} \mathrm{O}_{17} \mathrm{Cl}_{2}$ nanotubes self-accelerating charge separation for boosting photocatalytic $\mathrm{CO}_{2}$ reduction. Angew. Chem. Int. Ed. 57, 14847-14851 (2018).

35. Di, J. et al. Bismuth vacancy-tuned bismuth oxybromide ultrathin nanosheets toward photocatalytic $\mathrm{CO}_{2}$ reduction. ACS Appl. Mater. Interfaces 11, 30786-30792 (2019).

36. Neaţu, Ş., Maciá-Agulló, J. A., Concepción, P. \& Garcia, H. Gold-copper nanoalloys supported on $\mathrm{TiO}_{2}$ as photocatalysts for $\mathrm{CO}_{2}$ reduction by water. J. Am. Chem. Soc. 136, 15969-15976 (2014).

37. Wang, L., Jin, P., Huang, J., She, H. \& Wang, Q. Integration of copper(II)-porphyrin zirconium metalorganic framework and titanium dioxide to construct Z-scheme system for highly improved photocatalytic $\mathrm{CO}_{2}$ reduction. ACS Sustain. Chem. Eng. 7, 15660-15670 (2019).

38. Wang, Y. et al. Visible-light driven overall conversion of $\mathrm{CO}_{2}$ and $\mathrm{H}_{2} \mathrm{O}$ to $\mathrm{CH}_{4}$ and $\mathrm{O}_{2}$ on 3D-SiC@2D$\mathrm{MoS}_{2}$ heterostructure. J. Am. Chem. Soc. 140, 14595-14598 (2018).

39. Zhao, Y. et al. Graphene-wrapped $\mathrm{Pt} / \mathrm{TiO}_{2}$ photocatalysts with enhanced photogenerated charges separation and reactant adsorption for high selective photoreduction of $\mathrm{CO}_{2}$ to $\mathrm{CH}_{4}$. Appl. Catal. $\mathrm{B}$ 226, 360-372 (2018).

40. Game, O. et al. Concurrent synthetic control of dopant (nitrogen) and defect complexes to realize broadband (UV-650 nm) absorption in ZnO nanorods for superior photo-electrochemical performance. J. Mater. Chem. 22, 17302-17310 (2012).

41. Gelderman, K., Lee, L. \& Donne, S. W. Flat-band potential of a semiconductor: using the MottSchottky equation. J. Chem. Educ. 84, 685-688 (2004).

42. Zhou, P., Yu, J. \& Jaroniec, M. All-solid-state Z-scheme photocatalytic systems. Adv. Mater. 26, 49204935 (2014).

43. Wang, J.-C. et al. Enhanced photoreduction $\mathrm{CO}_{2}$ activity over direct Z-scheme a- $-\mathrm{Fe}_{2} \mathrm{O}_{3} / \mathrm{Cu}_{2} \mathrm{O}$ heterostructures under visible light irradiation. ACS Appl. Mater. Interfaces 7, 8631-8639 (2015).

44. Wang, Q. et al. Scalable water splitting on particulate photocatalyst sheets with a solar-to-hydrogen energy conversion efficiency exceeding 1\%. Nat. Mater. 15, 611-615 (2016).

45. Shi, $\mathrm{H}$. et al. Interfacial charge transfer in $\mathrm{OD} / 2 \mathrm{D}$ defect-rich heterostructures for efficient solar-driven $\mathrm{CO}_{2}$ reduction. Appl. Catal. B 245, 760-769 (2019).

46. Zhang, T., Low, J., Koh, K., Yu, J. \& Asefa, T. Mesoporous $\mathrm{TiO}_{2}$ comprising small, highly crystalline nanoparticles for efficient $\mathrm{CO}_{2}$ reduction by $\mathrm{H}_{2}$ O. ACS Sustainable Chem. Eng. 6, 531-540 (2018).

47. Zhang, $\mathrm{T}$. et al. Single atomic $\mathrm{Cu}-\mathrm{N}_{2}$ catalytic sites for highly active and selective hydroxylation of benzene to phenol. iScience 22, 97-108 (2019).

48. Sudrajat, $\mathrm{H}$. Unraveling structural properties of $\mathrm{Cu}_{2} \mathrm{O}$ loaded on $\mathrm{gC}_{3} \mathrm{~N}_{4}$ for enhanced photocatalytic hydrogen generation. Mater. Res. Express 5, 065519 (2018). 
49. Li, Y., Li, B., Zhang, D., Cheng, L. \& Xiang, Q. Crystalline carbon nitride supported copper single atoms for photocatalytic $\mathrm{CO}_{2}$ reduction with nearly $100 \%$ CO selectivity. ACS Nano 14, 10552-10561 (2020).

\section{Figures}

(a)

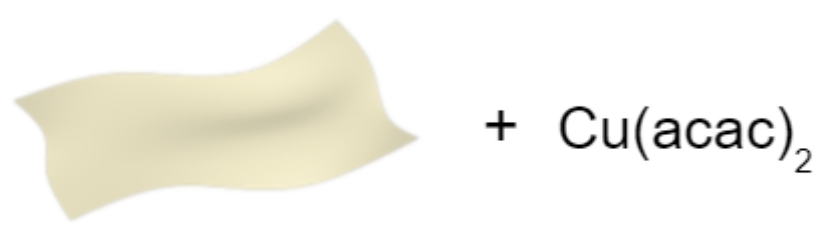

$$
\mathrm{g}-\mathrm{C}_{3} \mathrm{~N}_{4}
$$
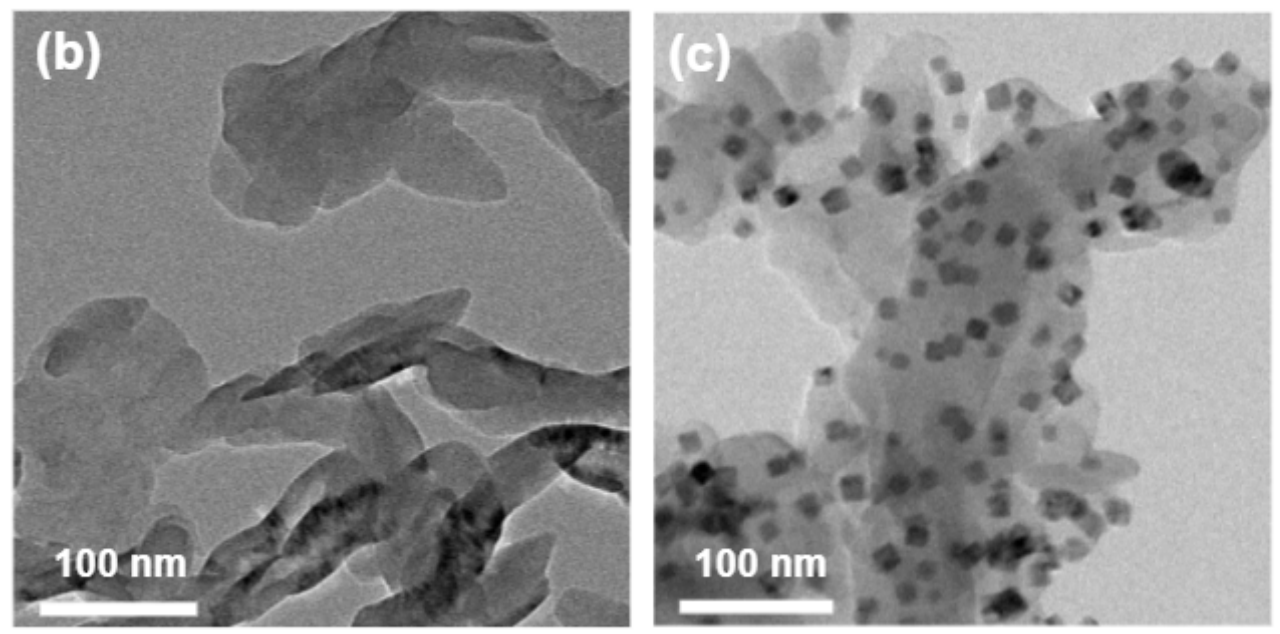
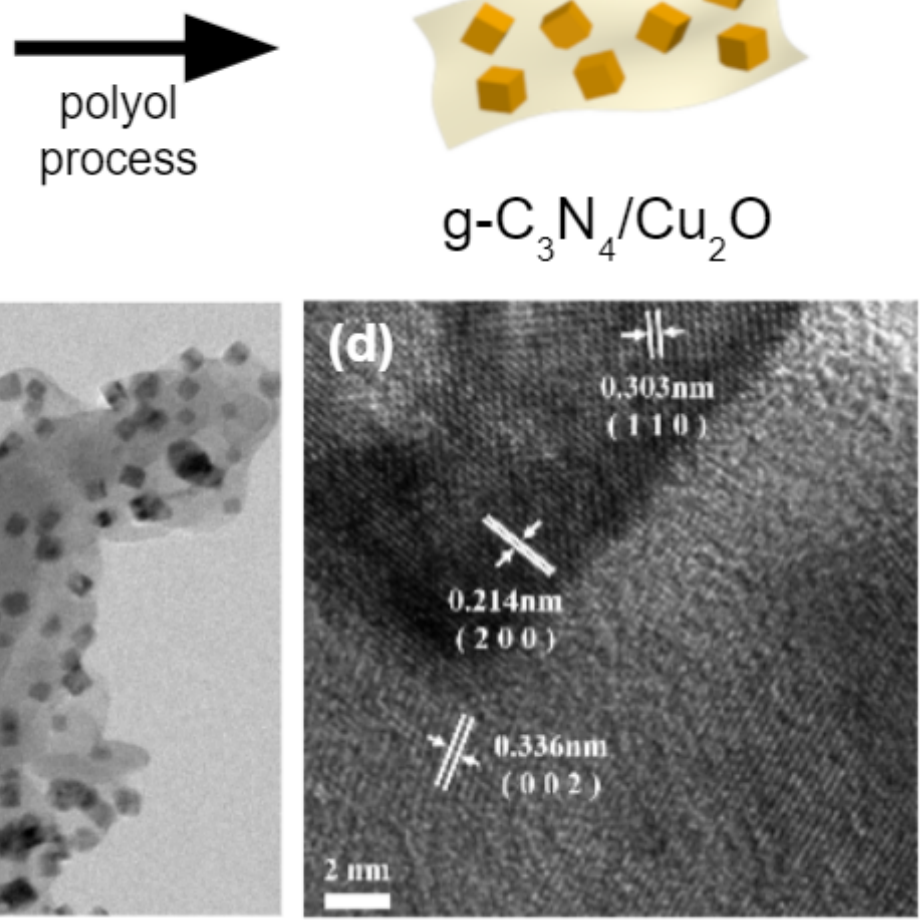

\section{Figure 1}

Direct growth of $\mathrm{Cu}_{2} \mathrm{O}$ nanocubes on $\mathbf{g}-\mathrm{C}_{3} \mathrm{~N}_{4}$. (a) Synthetic scheme of g- $\mathrm{C}_{3} \mathrm{~N}_{4} / \mathrm{Cu}_{2} \mathrm{O}$. TEM images of (b) g$\mathrm{C}_{3} \mathrm{~N}_{4}$ nanosheets and (c) g- $\mathrm{C}_{3} \mathrm{~N}_{4} / \mathrm{Cu}_{2} \mathrm{O}$ hybrid. (d) HRTEM image of $\mathrm{g}-\mathrm{C}_{3} \mathrm{~N}_{4} / \mathrm{Cu}_{2} \mathrm{O}$. 
(a)

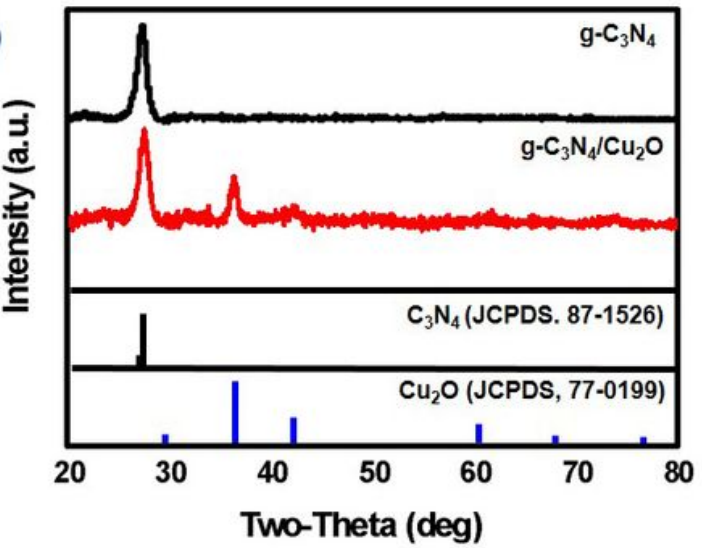

(b)

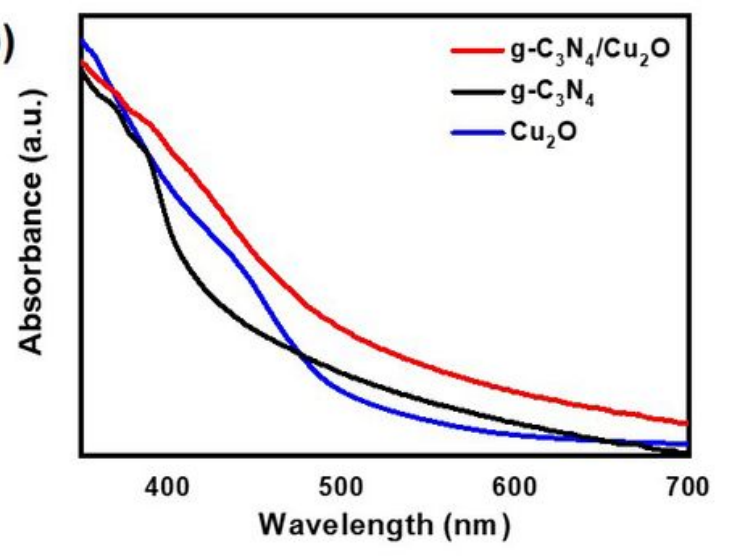

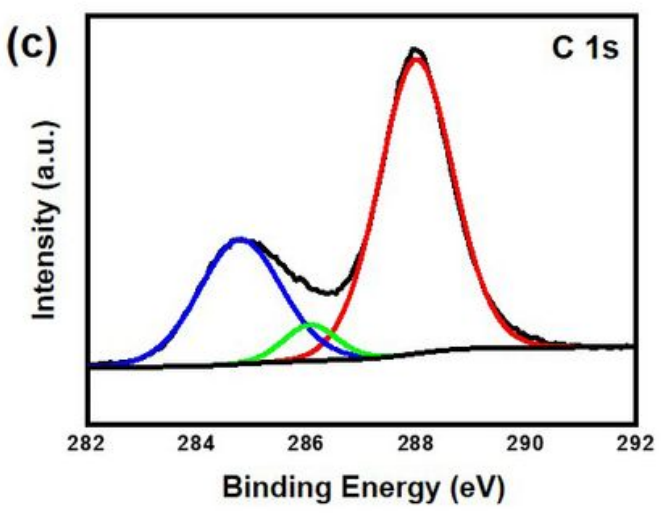
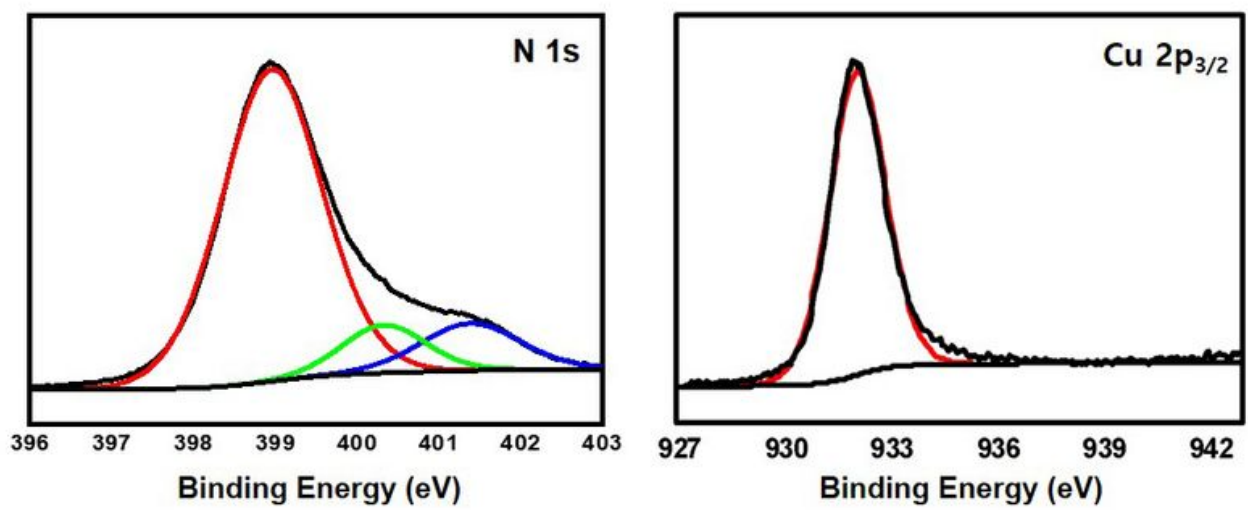

Figure 2

Characterization of g-C $\mathrm{C}_{3} \mathrm{~N}_{4} / \mathrm{Cu}_{2} \mathrm{O}$. (a) XRD and (b) UV-visible spectra of g- $\mathrm{C}_{3} \mathrm{~N}_{4}$ sheets, $\mathrm{Cu}_{2} \mathrm{O}$ nanocubes, and g- $\mathrm{C}_{3} \mathrm{~N}_{4} / \mathrm{Cu}_{2} \mathrm{O}$ hybrid. (c) XPS spectra of $\mathrm{g}-\mathrm{C}_{3} \mathrm{~N}_{4} / \mathrm{Cu}_{2} \mathrm{O}$. 
(a)

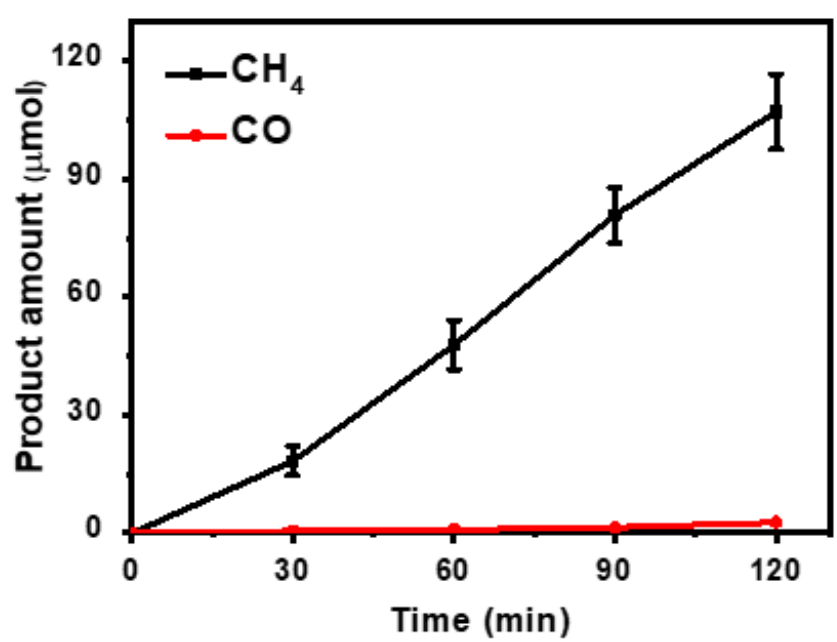

(c)

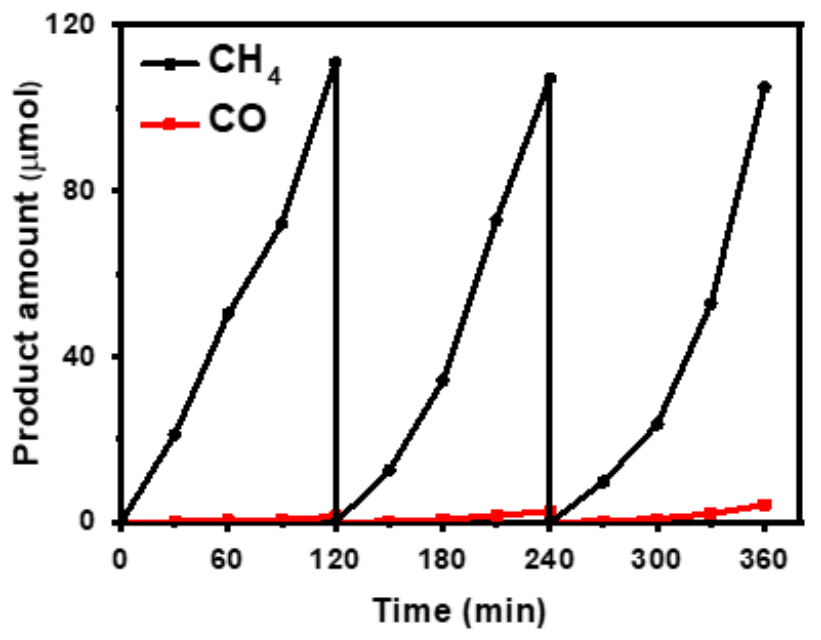

(b)

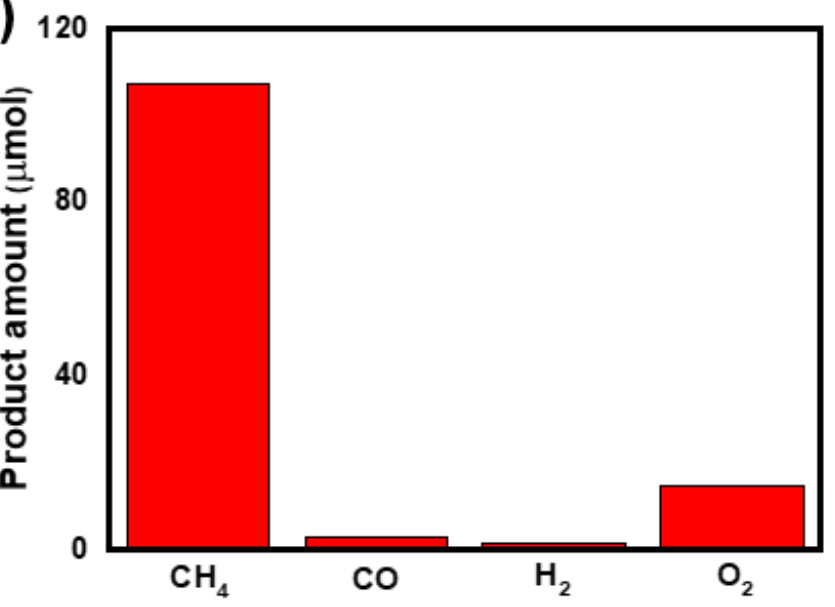

(d)

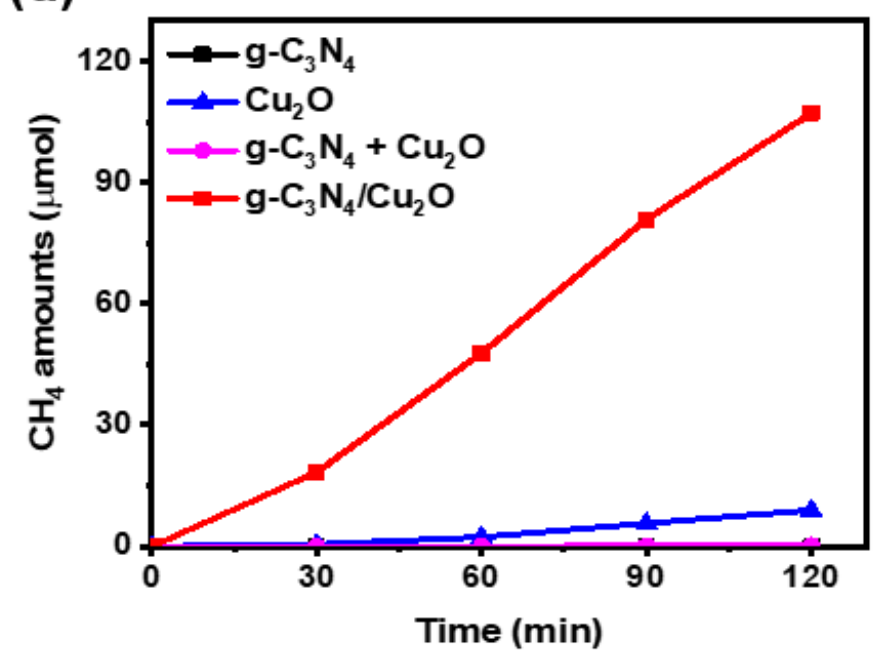

Figure 3

Photocatalytic $\mathrm{CO}_{2} \mathrm{RR}$ using g- $\mathrm{C}_{3} \mathrm{~N}_{4} / \mathrm{Cu}_{2} \mathrm{O}$. (a) Photocatalytic production of $\mathrm{CH}_{4}$ and $\mathrm{CO}$ as a function of irradiation time, and (b) the amounts of the gaseous products after the two-hour reaction. (c) Photocatalytic production of $\mathrm{CH}_{4}$ and $\mathrm{CO}$ by repetitive two-hour-reaction cycles. (d) $\mathrm{CH}_{4}$ evolution using different catalyst combinations. 
(a)

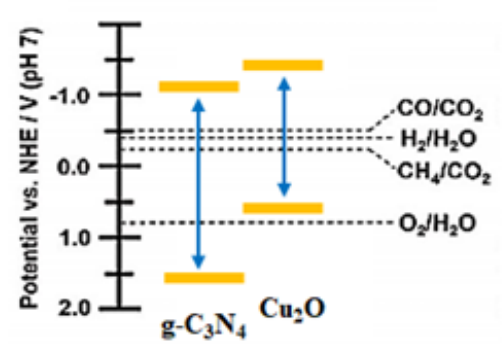

(d)

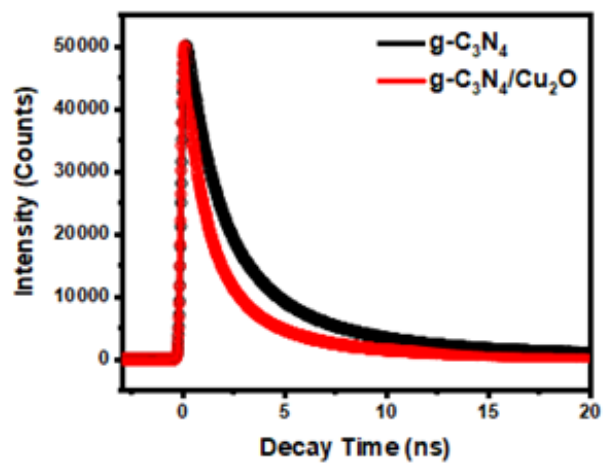

(b)

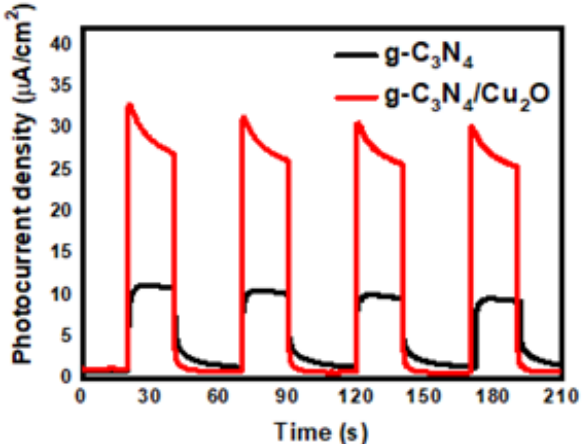

(e)

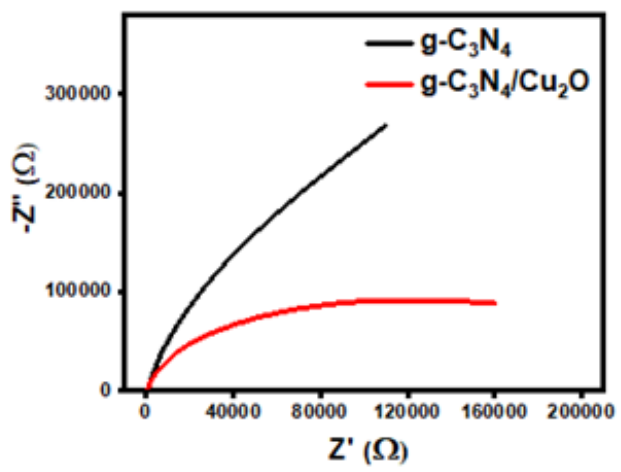

(c)

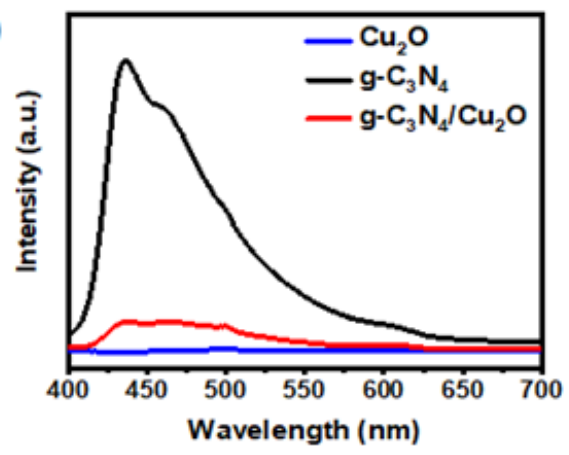

(f)

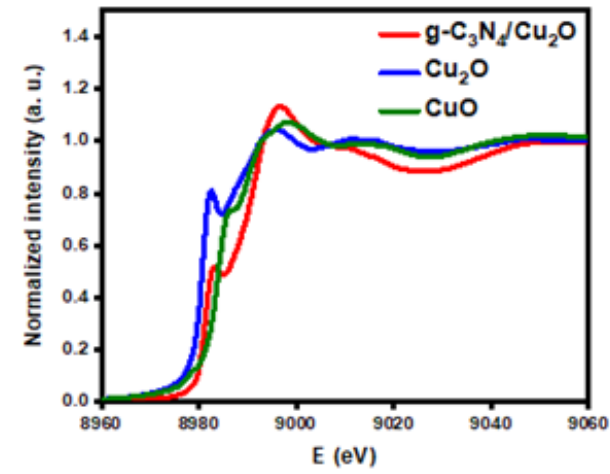

Figure 4

Photochemical reaction pathway and charge transfer through junctions. (a) Band diagram of the g$\mathrm{C}_{3} \mathrm{~N}_{4} / \mathrm{Cu}_{2} \mathrm{O}$ catalyst with standard electrochemical reduction potentials of the related reactions at $\mathrm{pH} 7$.

(b) Current-time photoresponse curves in $0.1 \mathrm{M}$ phosphate buffer solution, (c) steady PL spectra with 375 $\mathrm{nm}$ excitation, (d) TCSPC monitored at $440 \mathrm{~nm}$, (e) EIS Nyquist plots, and (f) normalized Cu K-edge XANES spectra of $\mathrm{Cu}_{2} \mathrm{O}$ (blue), $\mathrm{CuO}$ (green) and $\mathrm{g}-\mathrm{C}_{3} \mathrm{~N}_{4} / \mathrm{Cu}_{2} \mathrm{O}$ hybrid (red).

\section{Supplementary Files}

This is a list of supplementary files associated with this preprint. Click to download.

- C3N4Cu2OSupplement.docx 